\title{
Targeted triangular resection for repair of degenerative mitral valve disease
}

\author{
Daniel J. P. Burns, MD, MPhil, Rakesh M. Suri, MD, DPhil, and A. Marc Gillinov, MD
}

Video clip is available online.

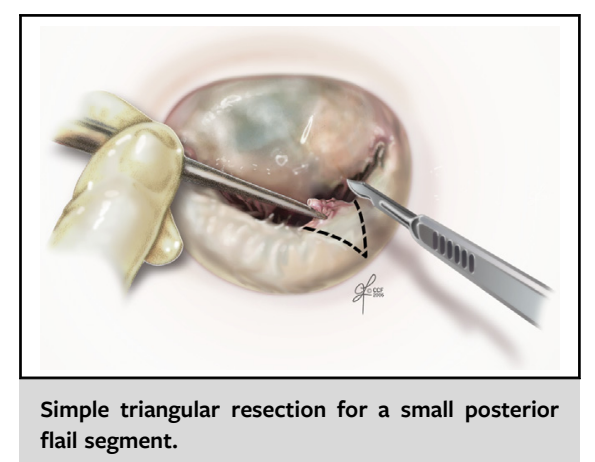

For patients with primary mitral regurgitation (MR) secondary to degenerative mitral valve disease, mitral valve repair is the gold standard therapy. The benefits of mitral valve repair in patients with degenerative disease are well established. In addition to superior survival, a complete mitral valve repair decreases risks of thromboembolism, endocarditis, anticoagulant-related hemorrhage, and reintervention relative to valve replacement. ${ }^{1-4}$ Many mitral valve repair techniques are available to the surgeon, with varying degrees of complexity, that should result in a successful valve repair $>90 \%$ of the time. Of these techniques, we are going to focus this discussion on one of the most practical: the triangular resection. We will begin with the initial considerations of every valve repair and move on to the specific techniques and nuances of performing a mitral valve repair using a targeted triangular resection.

\section{UNDERSTANDING AND EXPOSING THE VALVE}

Before undertaking any attempt at mitral valve repair, careful examination of the intraoperative transesophageal echocardiogram (TEE) is essential. The exact mechanism of MR can be determined by careful examination of both 2-dimensional and 3-dimensional imaging. Sites of prolapse/flail and degree of excess leaflet tissue should be evident. With the addition of color Doppler, jet volume and direction can confirm the major lesion present and help uncover any additional sites of regurgitation that may need to be addressed, such as prominent indentations between segments. The other important function performed

\footnotetext{
From the Department of Thoracic and Cardiovascular Surgery, Cleveland Clinic, Cleveland, Ohio.

Received for publication Aug 9, 2021; accepted for publication Sept 27, 2021; available ahead of print Oct 2, 2021.

Address for reprints: Daniel J.P. Burns, MD, MPhil, Department of Thoracic and Cardiovascular Surgery, Cleveland Clinic, 9500 Euclid Ave/J4-1, Cleveland, OH 44195 (E-mail: burnsd@ccf.org).

JTCVS Techniques 2021;10:47-52

2666-2507

Copyright (C) 2021 The Author(s). Published by Elsevier Inc. on behalf of The American Association for Thoracic Surgery. This is an open access article under the CC BY-NC-ND license (http://creativecommons.org/licenses/by-nc-nd/4.0/).

https://doi.org/10.1016/j.xjtc.2021.09.049
}

by intraoperative TEE is the determination of the risk of postrepair systolic anterior motion (SAM) of the anterior leaflet. Basal septal thickness $\geq 15 \mathrm{~mm}$, a narrow left ventricular outflow tract (septum to coaptation point $<25 \mathrm{~mm}$, aortomitral angle $<120^{\circ}$ ), a small ventricle (end diastolic diameter $<45 \mathrm{~mm}$ ), and posterior leaflet length $\geq 15 \mathrm{~mm}$ all have been shown to predict SAM following mitral valve repair. ${ }^{5}$ If SAM is present before repair, we favor planning for an extensive resection-based repair. With proper planning and TEE assessment, the proper repair techniques can be chosen and the risk of postoperative SAM mitigated.

The first step to any mitral valve repair is obtaining the necessary valve exposure. Exposure maneuvers will differ somewhat depending on the initial operative approach. In a sternotomy-based approach, after entering into the pericardium, stay sutures are placed on the right side only, allowing the heart to roll left. Standard aortobicaval cannulation is typically performed, although single right atrial venous cannulation with a multistage cannula can be used as well. Certain techniques can further enhance exposure. These include freeing up the tissue surrounding the superior vena cava, opening the oblique sinus, and/or 
placing a snare around the inferior vena cava cannula and distracting it inferiorly under mild tension. After the heart is arrested, we prefer a left atriotomy, although in certain deep or obese patients, a trans-septal approach may be preferred. If a transseptal approach is inadequate, the incision can be carried over the dome of the left atrium. This provides excellent exposure, although it predisposes to postoperative rhythm disturbances due to invariably dividing the artery to the sinoatrial node.

In the case of right thoracic approaches to the mitral valve, the direct line of sight along with the transthoracic left atrial retractor almost always results in excellent exposure. Whichever approach is used, it is worth spending extra minutes optimizing valve exposure, as this will directly affect the surgeon's ability to inspect/assess the valve, as well as carry out the necessary repair.

\section{ANNULOPLASTY SUTURES AND VALVE INSPECTION}

In sternotomy approaches, it is our practice to first place annuloplasty sutures. This will enhance exposure and allow a more complete initial valve inspection. If required, placing the sutures under slight tension will elevate the valve and bring it closer to the surgeon, enhancing exposure/access and potentially "unfurling" a compressed valve. This can also apply to nonsternotomy approaches when using interrupted annuloplasty sutures, although manipulation of the transthoracic left atrial retractor is generally all that is needed to optimize exposure, given the direct line of sight.

Once annuloplasty sutures are placed, a comprehensive valve assessment can be performed, with the site of valve prolapse identified and quantified. Keeping in mind the findings of the intraoperative TEE, the surgeon systematically inspects each valve segment, identifying the segment(s) of abnormal valve. It can be useful to identify a normal valve segment as a reference point, used to judge relative differences in segment height, thickness, and overall tissue redundancy. This is a crucial component of planning the mitral valve repair, and also an important crossroads. Once the valve has been inspected, we can classify it as simple or complex. In agreement with contemporary guidelines, disease of $>1$ posterior segment, anterior leaflet disease, or bileaflet disease is classified as complex, while single segment prolapse or flail of the posterior leaflet is considered simple. ${ }^{6}$ A targeted triangular resection for mitral valve repair is best suited for a "simple" valve lesion. Complex valve lesions typically require a more extensive repair utilizing advanced techniques, alone or in combination.

\section{TARGETED TRIANGULAR RESECTIONS OF THE POSTERIOR LEAFLET}

If a simple valve lesion is identified, a targeted triangular resection is an excellent technique for mitral valve repair. ${ }^{8}$
A properly performed triangular resection will be targeted toward the specific area of leaflet pathology, will decrease both leaflet height and volume, and will result in a tension-free repair. ${ }^{9}$ Depending on the extent of leaflet disease, these resections may be small, more extensive, or even asymmetric. In all cases, the boundaries of the abnormal valve segment are first identified along with adjacent normal chords. This technique can be employed in segmental prolapse of any of P1, P2, or P3. However, if the prolapsing segment approaches the commissural region, alternative or adjunctive techniques will likely be required. ${ }^{8}$ Targeted small triangular resection of the anterior leaflet has been described, and reported with success. ${ }^{10-12}$ However, it is our opinion that anterior leaflet pathology is better addressed with chordal-based repair techniques. ${ }^{7,8,13,14}$

\section{Simple Triangular Resection}

This technique is best used for segmental posterior prolapse without grossly excessive leaflet tissue or for an isolated small flail segment secondary to chordal rupture in fibroelastic deficiency. Traditionally, this has been described as being when the free margin of the diseased segment is approximately one-third or less of the total segment length. The boundaries of the abnormal segment are identified, and the adjacent normal chords are isolated by placing stay sutures around the chords. This defines the boundaries of abnormal tissue and elevates the diseased segment for subsequent resection and reconstruction. A small symmetric triangular resection is performed. The depth of the resection, the apex of the triangle, should be slightly longer than the base of the triangular resection at the free edge. The depth of the resection will likely not reach the annulus in this method. ${ }^{9,11}$ The lateral margins of the resection may be slightly scalloped to ensure a tension free reconstruction when the leaflet edges are reapproximated. ${ }^{12}$ Once the resection is completed, the free margins at the base of the resection (the leaflet free edge) are reapproximated, and the defect is closed with interrupted or running polypropylene suture. The repair is completed with the implantation of the annuloplasty prosthetic (Figure 1).

\section{Extensive Triangular Resection}

When excessive leaflet tissue is present in a segmental posterior prolapse, a more extensive triangular resection may be required. This is done to ensure that both the volume and height of the leaflet are reduced, providing a competent valve and avoiding SAM. ${ }^{9}$ The same initial steps apply: identify the extent of the leaflet disease, then identify and isolate the adjacent normal chordae. The triangular resection will necessarily be wider and deeper toward the annulus to adequately remove/reduce the abnormal tissue. Reconstruction of the posterior leaflet takes place as previously described, using running or interrupted polypropylene 


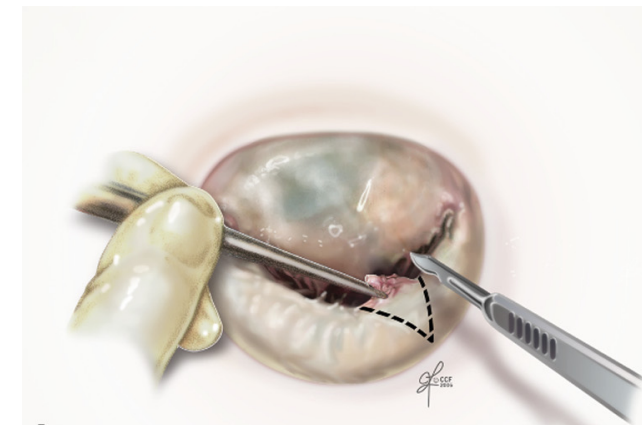

A

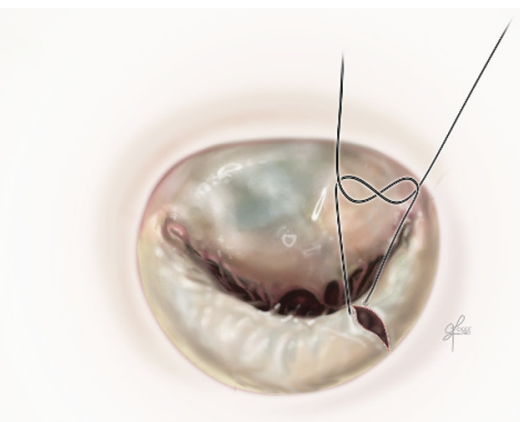

B

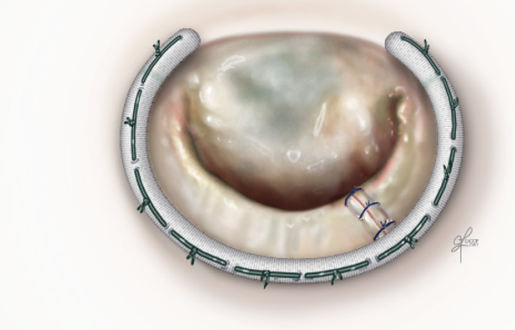

C

FIGURE 1. A, Performance of a simple triangular resection for a flail segment of posterior leaflet. B, Reapproximating the valve free edge at the base of the resection. C, Completion of the simple triangular resection including leaflet reconstruction and annuloplasty implantation.

suture (Figure 2, Video 1). With all extensive triangular resections, care must be taken to not remove too much leaflet tissue. Excessive tissue removal will create tension on the reconstructed leaflet. This will have the effect of either tethering/restricting the posterior leaflet, or creating a shallow and stiff posterior "shelf," both leading to inadequate leaflet coaptation. ${ }^{12}$ Ultimately, this can lead to suboptimal operative results; residual MR may be present which, along with inadequate coaptation, can lead to poorer repair durability. The best way to manage this problem is, of course, to prevent it. Before resection, the surgeon can estimate the end result by approximating the adjacent normal chordae, seeing how the reconstruction will come together. If the leaflet is poorly mobile, excessively flattened, or distorting adjacent segments, then too much tissue is going to be removed. If faced with this result after resection, this would be best addressed by converting to the more extensive sliding plasty-based repair. Judgment is key here, and it is better to err on the side of removing less tissue.

In certain cases of excessive posterior leaflet tissue, an extensive resection may reduce the volume of tissue but inadequately reduce the leaflet height, leading to postrepair SAM if not addressed. In these cases, we favor a ventricularization technique to reduce the height of the reconstructed posterior leaflet. ${ }^{15}$ In this technique, the free edges of the resection are not simply reapproximated. Rather, the free edges at the base of the resection are folded onto their respective ventricular aspects in order to decrease the height of the reconstructed free edge. Following the resection, each end of a double armed suture is placed from the atrial to the ventricular side through the respective free edge at the resection base. Each needle is then brought back up through the resected edge of its respective side posteriorly, toward the annulus. ${ }^{8} 16$ When this suture is tied, it buries or "ventricularizes" the leading edge, thereby decreasing the height of the posterior leaflet (Figure 3, Video 2). This technique not only reduces leaflet height but also allows the equalization of an asymmetric resection if required. Following completion of the initial ventricularization, the remaining suture ends are used to complete a standard 2-layer closure, completing the leaflet reconstruction. As always, the repair is completed with the implantation of an annuloplasty prosthetic.

The previously described techniques have assumed that the triangular resection performed is symmetric, and that there is an equal tissue volume and height remaining on either side of the posterior leaflet resection. While this is commonly the case with segmental leaflet prolapse, excess tissue can be asymmetric, or there may be deep clefts between valve segments present. In these cases, a typical triangular resection may not result in an adequate posterior leaflet reconstruction. When faced with cases such as these, the previously described ventricularization technique works well. Different respective degrees of leaflet 


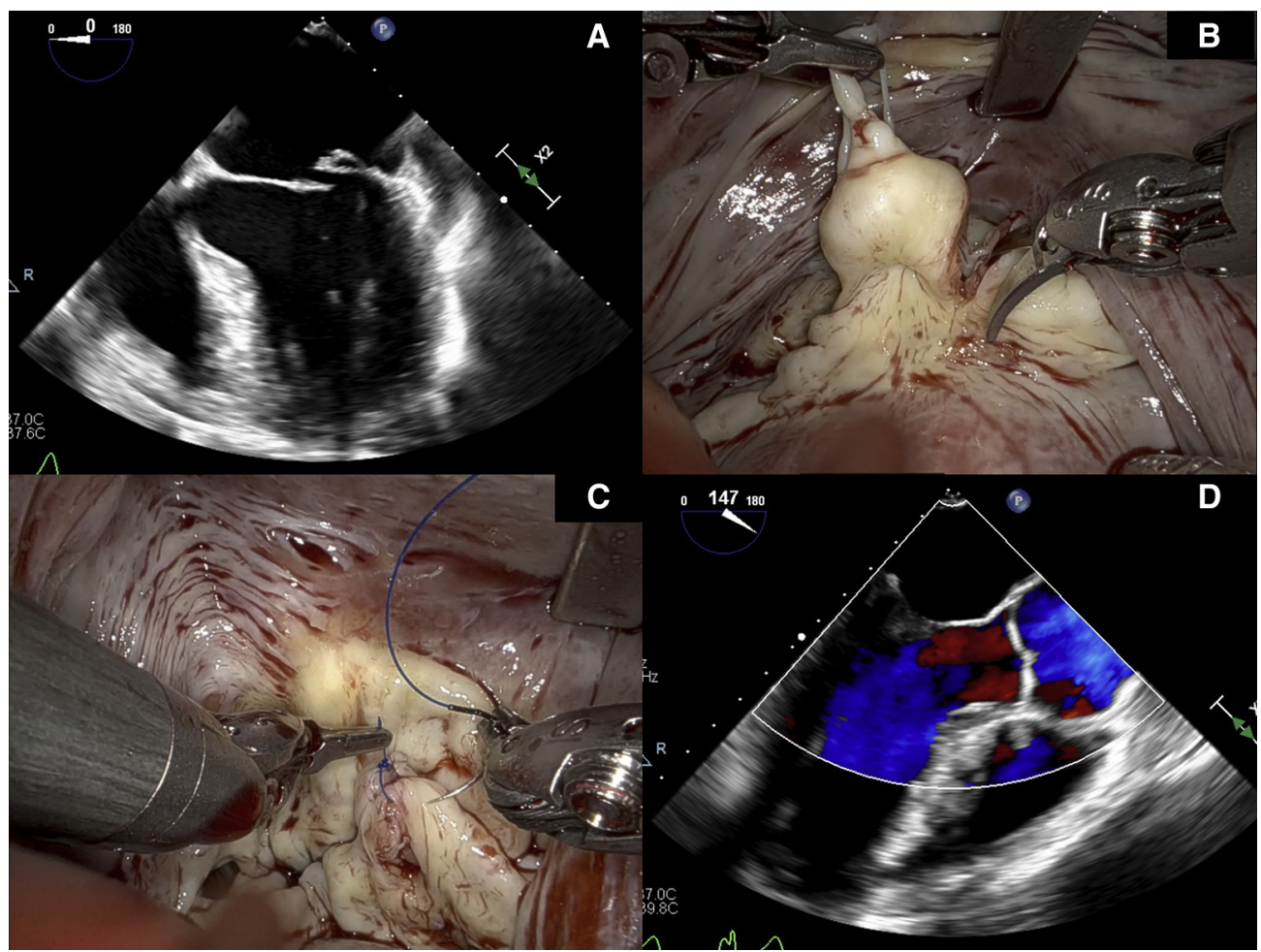

FIGURE 2. Extensive triangular resection for advanced segmental degenerative disease. A, Intraoperative transesophageal echocardiogram demonstrating the flail segment. B, Performing the triangular resection. C, Performing the leaflet reconstruction using interrupted polypropylene sutures. D, Completed repair without residual regurgitation or systolic anterior motion.

ventricularization for each side of the resection allows the free edge of the reconstructed leaflet to be equalized when the repair is completed. Alternatively, one side of the asymmetric resection can be focused on a deep cleft between valve segments. ${ }^{9}$ The cleft serves as one of the lateral resection margins, with the remainder of the resection involving the diseased leaflet segment. The leaflet reconstruction

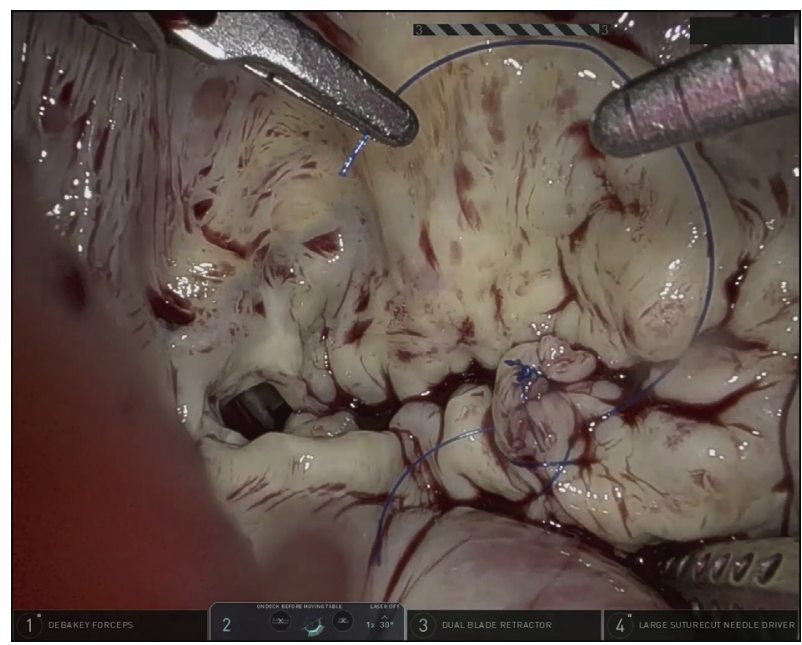

VIDEO 1. Triangular resection with reconstruction using interrupted sutures. Video available at: https://www.jtcvs.org/article/S2666-2507(21) 00681-7/fulltext. takes place in a standard manner with polypropylene suture, unifying the unresected tissue on the cleft side with the resected edge of the diseased leaflet side.

A recently described technique can achieve a similar outcome to the ventricularization previously described. The "butterfly technique" serves as a bridge between the triangular resection and the more extensive quadrangular resection with sliding plasty. ${ }^{17}$ When faced with excessive leaflet height, an initial triangular resection is planned at a predefined height depending on whether $\mathrm{P} 2$ or $\mathrm{P} 1 / 3$ are involved. Additional smaller horizontal triangular resections are planned from the apex of the initial triangular resection, extending to the annular level. After completion of these resections, the leaflet margins are rotated toward the annulus, secured, and the leaflet reconstruction completed using polypropylene suture. We do not currently employ this technique, instead favoring leaflet ventricularization, adjunctive neochordae, or the more extensive quadrangular resection with sliding plasty. However, it is an elegant option to decrease posterior leaflet height, has sound physiologic reasoning, and demonstrates encouraging early results. ${ }^{18}$

\section{Adjunctive Procedures}

Once the valve repair has been completed, the valve undergoes conventional saline and ink testing to assess the 


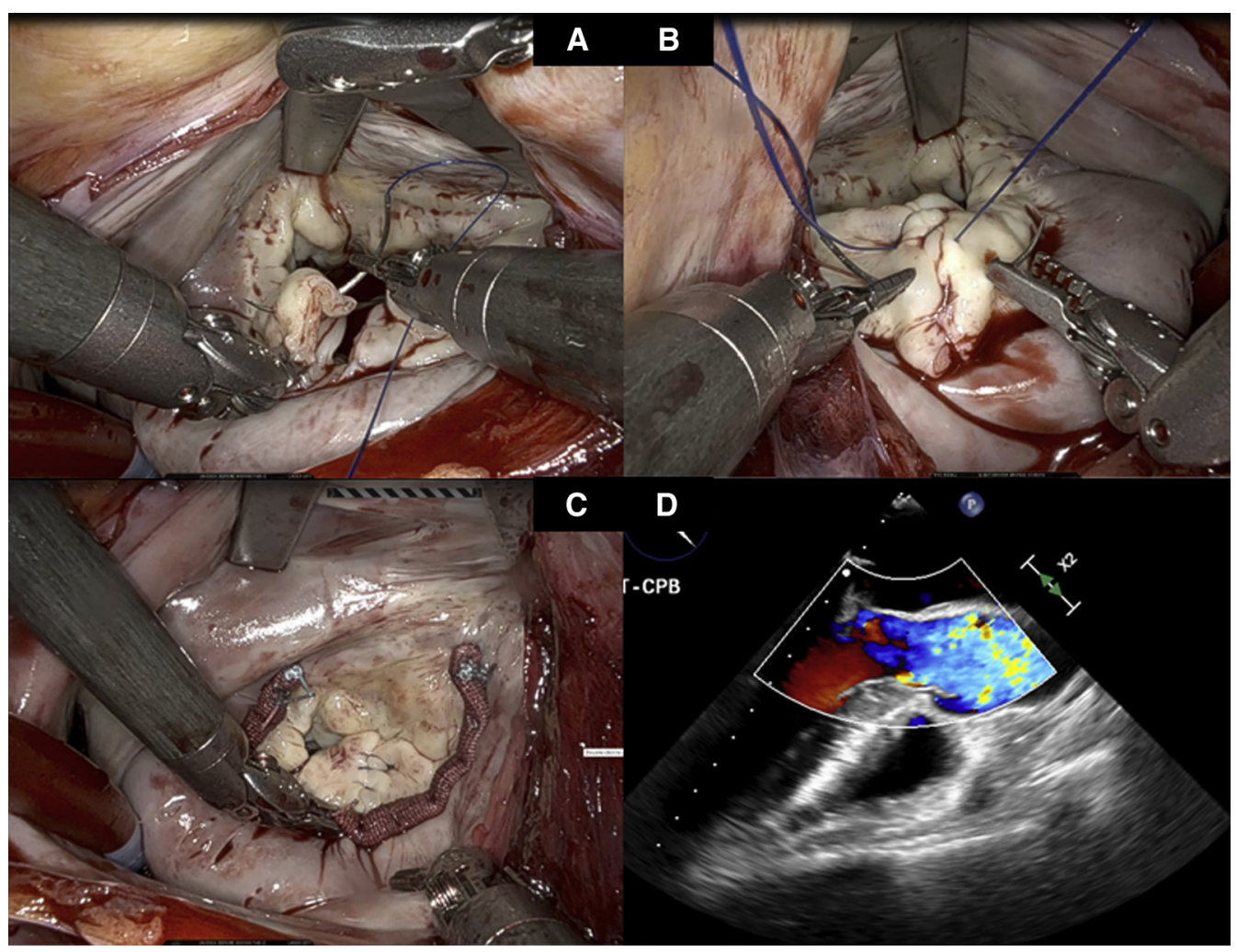

FIGURE 3. Extensive triangular resection with leaflet ventricularization. A, Ventricularizing the leaflet free edge as appropriate for required height reduction and/or equalization. B, Completing the leaflet reconstruction using running polypropylene suture. C, Completed repair following running annuloplasty. $\mathrm{D}$, Completed repair without residual regurgitation or systolic anterior motion.

repair adequacy prior to closing the cardiac chamber(s) and weaning from cardiopulmonary bypass. Following a triangular resection, the surgeon is looking for a competent valve with an adequately posterior coaptation point. If coaptation is not adequately posterior, then SAM may be observed

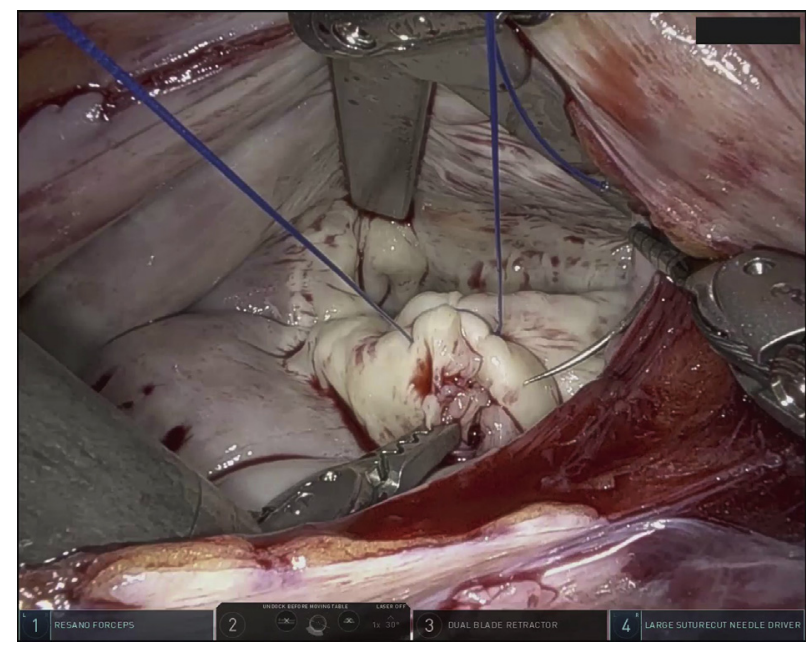

VIDEO 2. Triangular resection reconstructed using the ventricularization technique. Video available at: https://www.jtcvs.org/article/S26662507(21)00681-7/fulltext. once weaned from cardiopulmonary bypass. Although there are accepted algorithms for medically managing SAM, tailoring the operative strategy to predict and avoid SAM is preferable. ${ }^{5,19}$ Performing a leaflet ventricularization to decrease posterior leaflet height in those with an increased anticipated risk of SAM should be employed during a triangular resection. If despite the surgeon's best effort, coaptation is excessively anterior ( $\geq 50 \%$ of the valve orifice), the posterior leaflet is excessively tall $(\geq 15 \mathrm{~mm})$, or if SAM is unexpectedly encountered after weaning from cardiopulmonary bypass, decreasing the relative leaflet height with the addition of neochordae is preferable to revising the entire repair.

When leaflet degeneration is more extensive, adjacent segments may show signs of early degeneration, and the usual indentations between valve segments may develop into deeper clefts, occasionally extending to the annular level. These can lead to significant residual MR following repair with a triangular resection, as the reconstruction following triangular resection can pull apart these clefts. These can be easily managed by primarily closing the offending cleft using polypropylene suture. Alternatively, the resection margin can be fashioned to include the cleft as described previously. 


\section{RESULTS}

Mitral valve repair is the gold standard for degenerative mitral valve disease, with excellent survival and durability expecte. ${ }^{1,4,20,21}$ For simple segmental posterior leaflet prolapse, triangular resection has been similarly shown to be a safe and effective technique with excellent long-term results. ${ }^{22,23}$ Using a triangular resection, freedom from mitral valve reintervention at 10 to 20 years should be expected to exceed $90 \%$, and it may hold advantages over the more extensive quadrangular resection when appropriately used. $^{1,23,24}$ By employing the discussed techniques, one can be expected to achieve excellent operative and postoperative results. This has the net effect of translating into improved long-term outcomes for our mitral valve patients.

\section{Conflict of Interest Statement}

D.J.P.B. is a consultant for Medtronic. A.M.G. is a consultant to Medtronic, Edwards Lifesciences, Abbott, CryoLife, Johnson and Johnson, AtriCure, and ClearFlow and has right to equity from ClearFlow. R.M.S. reported no conflicts of interest.

The Journal policy requires editors and reviewers to disclose conflicts of interest and to decline handling or reviewing manuscripts for which they may have a conflict of interest. The editors and reviewers of this article have no conflicts of interest.

\section{References}

1. David TE, David CM, Tsang W, Lafreniere-Roula M, Manlhiot C. Long-term results of mitral valve repair for regurgitation due to leaflet prolapse. J Am Coll Cardiol. 2019;74:1044-53.

2. Gillinov AM, Blackstone EH, Nowicki ER, Slisatkorn W, Al-Dossari G, Johnston DR, et al. Valve repair versus valve replacement for degenerative mitral valve disease. J Thorac Cardiovasc Surg. 2008;135:885-93. 893.

3. Suri RM, Schaff HV, Dearani JA, Sundt TM, Daly RC, Mullany CJ, et al. Survival advantage and improved durability of mitral repair for leaflet prolapse subsets in the current era. Ann Thorac Surg. 2006;82:819-26.

4. Braunberger E, Deloche A, Berrebi A, Abdallah F, Celestin JA, Meimoun P, et al. Very long-term results (more than 20 years) of valve repair with Carpentier's techniques in nonrheumatic mitral valve insufficiency. Circulation. 2001; 104(suppl 1):I8-11.

5. Varghese R, Itagaki S, Anyanwu AC, Trigo P, Fischer G, Adams DH. Predicting systolic anterior motion after mitral valve reconstruction: using intraoperative transoesophageal echocardiography to identify those at greatest risk. Eur J Cardiothorac Surg. 2014;45:132-7.

6. Otto CM, Nishimura RA, Bonow RO, Carabello BA, Erwin JP, Gentile F, et al. 2020 ACC/AHA guideline for the management of patients with valvular heart disease: a report of the American College of Cardiology/American Heart Association joint committee on clinical practice guidelines. Circulation. 2021;143: e72-227.

7. Suri RM, Taggarse A, Burkhart HM, Daly RC, Mauermann W, Nishimura RA, et al. Robotic mitral valve repair for simple and complex degenerative disease: midterm clinical and echocardiographic quality outcomes. Circulation. 2015; 132:1961-8.

8. Chemtob RA, Wierup P, Mick S, Gillinov M. Choosing the "Best" surgical techniques for mitral valve repair: lessons from the literature. J Card Surg. 2019;34: 717-27.

9. Rimsukcharoenchai C, Pandis D, El-Eshmawi A, Anyanwu AC, Adams DH. Complex mitral valve regurgitation: surgical evaluation, approach and repair techniques. J Vis Surg. 2021;7:15.

10. Saunders PC, Grossi EA, Schwartz CF, Grau JB, Ribakove GH, Culliford AT, et al. Anterior leaflet resection of the mitral valve. Semin Thorac Cardiovasc Surg. 2004;16:188-93.

11. Gazoni LM, Fedoruk LM, Kern JA, Dent JM, Reece TB, Tribble CG, et al. A simplified approach to degenerative disease: triangular resections of the mitral valve. Ann Thorac Surg. 2007;83:1658-64.

12. Suri RM, Orszulak TA. Triangular resection for repair of mitral regurgitation due to degenerative disease. Oper Tech Thorac Cardiovasc Surg. 2005;10:194-9.

13. Schaff HV, Nguyen A. Contemporary techniques for mitral valve repair-the Mayo Clinic experience. Indian J Thorac Cardiovasc Surg. 2020;36(suppl 1): $18-26$.

14. Gillinov M, Burns DJP, Wierup P. The 10 commandments for mitral valve repair. Innovations (Phila). 2020;15:4-10.

15. Suri RM, Burkhart HM, Schaff HV. A novel method of leaflet reconstruction after triangular resection for posterior mitral valve prolapse. Ann Thorac Surg. 2010; 89:e53-6.

16. Javadikasgari H, Suri RM, Mihaljevic T, Mick S, Gillinov AM. Technical aspects of robotic posterior mitral valve leaflet repair. Ann Cardiothorac Surg. 2016;5: $577-81$.

17. Asai T. The butterfly technique. Ann Cardiothorac Surg. 2015;4:370-5.

18. Asai T, Kinoshita T, Suzuki T, Shiraishi S, Koike M. Early and follow-up results of butterfly resection of prolapsed posterior leaflet in 76 consecutive patients. J Thorac Cardiovasc Surg. 2015;149:1296-300.

19. Varghese R, Anyanwu AC, Itagaki S, Milla F, Castillo J, Adams DH. Management of systolic anterior motion after mitral valve repair: an algorithm. J Thorac Cardiovasc Surg. 2012;143(4 suppl):S2-7.

20. David TE. Durability of mitral valve repair for mitral regurgitation due to degenerative mitral valve disease. Ann Cardiothorac Surg. 2015;4:417-21.

21. Mohty D, Orszulak TA, Schaff HV, Avierinos JF, Tajik JA, Enriquez-Sarano M. Very long-term survival and durability of mitral valve repair for mitral valve prolapse. Circulation. 2001;104(suppl 1):1-7.

22. George KM, Mihaljevic T, Marc Gillinov A. Triangular resection for posterior mitral prolapse: rationale for a simpler repair. J Heart Valve Dis. 2009;18:119-21.

23. Sakamoto Y, Hashimoto K, Okuyama H, Ishii S, Kawada N, Inoue T, et al. Mitral valve reconstruction: long-term results of triangular resection for degenerative prolapse. Gen Thorac Cardiovasc Surg. 2008;56:63-7.

24. Sakamoto Y, Hashimoto K, Okuyama H, Ishii S, Hanai M, Inoue T, et al. Longterm assessment of mitral valve reconstruction with resection of the leaflets: triangular and quadrangular resection. Ann Thorac Surg. 2005;79:475-9.

Key Words: mitral valve, mitral valve repair, triangular resection 